\title{
Pervasive poleward shifts among North American bird species
}

\section{A. Townsend Peterson ${ }^{1}$ and Enrique Martínez-Meyer ${ }^{2}$}

AUTHORS' ADDRESSES:

${ }^{1}$ Natural History

Museum and

Biodiversity Research

Center, The University

of Kansas, Lawrence,

Kansas 66045 USA.

${ }^{2}$ Instituto de Biología,

Universidad Nacional

Autónoma de México,

México, D.F. 04510

México.

A
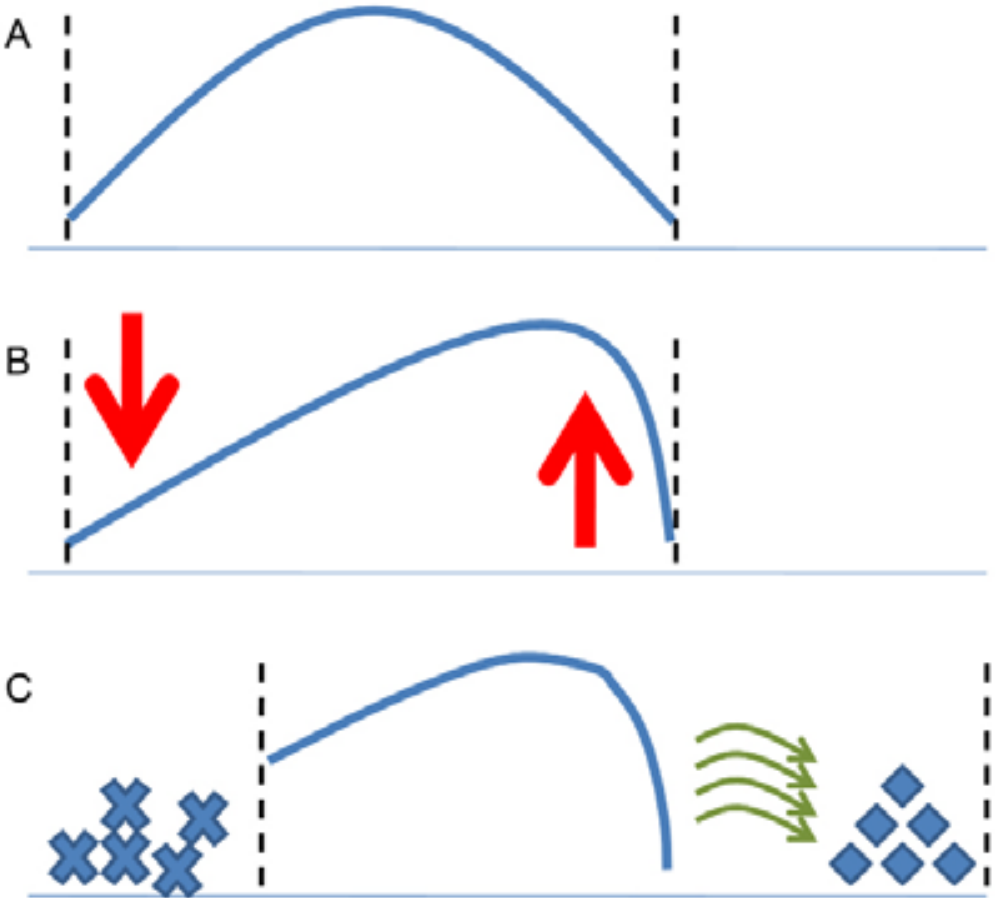

Equatorial

\section{Polar}

Figure 1. Hypothesized process of climate change effects on species' geographic distributions. Curved blue lines summarize approximate abundance of the species; black dashed lines indicate range limits; arrows indicate increases and decreases in fitness; and diamonds and X's indicate colonizing populations and extirpated populations, respectively. (A) "Normal" condition; (B) intermediate stage, in which numbers swell along poleward margin of species range, but reduce along equatorial margin; and (C) actual range shifts, consisting of poleward colonization, and equatorial-side extirpation.
Hannah 2005). Several studies have documented shifts fitting these expectations (Holt 1990; Root et al. 2003; Lovejoy and Hannah 2005), suggesting that elements of biodiversity are beginning to respond to warming climates (Parmesan 1996; Visser et al. 1998; Parmesan et al. 1999; Chapin et al. 2000; Walther et al. 2002; Crozier 2003; Parmesan and Yohe 2003; Perfors et al. 2003; Huntley et al. 2007), but the ubiquity of these responses is unclear.

The process of manifesting these shifts, particularly in terms of geographic distributions, can be conceptualized as a process of temporal differentials in fitness causing population swells and lows in different portions of the geographic distribution, followed by eventual extirpation of equatorial-side populations and colonization of new areas along the poleward side of the distribution (Fig. 1). Under this scheme, actual distributional shifts would be the last signal of climate change effects on species, and would not be detectable until late in the process, but would be preceded by population shifts within the original distributional area. Indeed, several analyses of distributional shifts as a function of climate change have detected only subtle distributional shifts (Parmesan 1996; Parmesan et al. 1999; Cresswell and McCleery 2003; Crozier 2003; Parmesan and Yohe 2003; Conti Nunes et al. 2007). In contrast, population shifts have not been analyzed on continental scales-the focus of this contribution-we show that numbers in about half of North American bird species are swelling poleward and declining on the equatorial sides of species' distributional areas, a trend that will eventually translate into real range shifts.

\section{MATERIALS AND METHODS}

Data for these analyses were obtained from the U.S. Breeding Bird Survey (BBS), drawing on survey results from the entire span of the survey (1966-present). We included only breeding bird species, and eliminated nonnative species from all analyses. We further reduced the working dataset by focusing on only those species for which $\geq 5$ occurrence localities were available, so as to analyze only those species for which sampling was sufficient for assessment of trends.

For each species in each year, we calculated the average latitude across all individuals as, where $x_{i j}$ is the number of individuals of species $i$ at site $j$, and $L_{j}$ is the latitude of site $j$. 


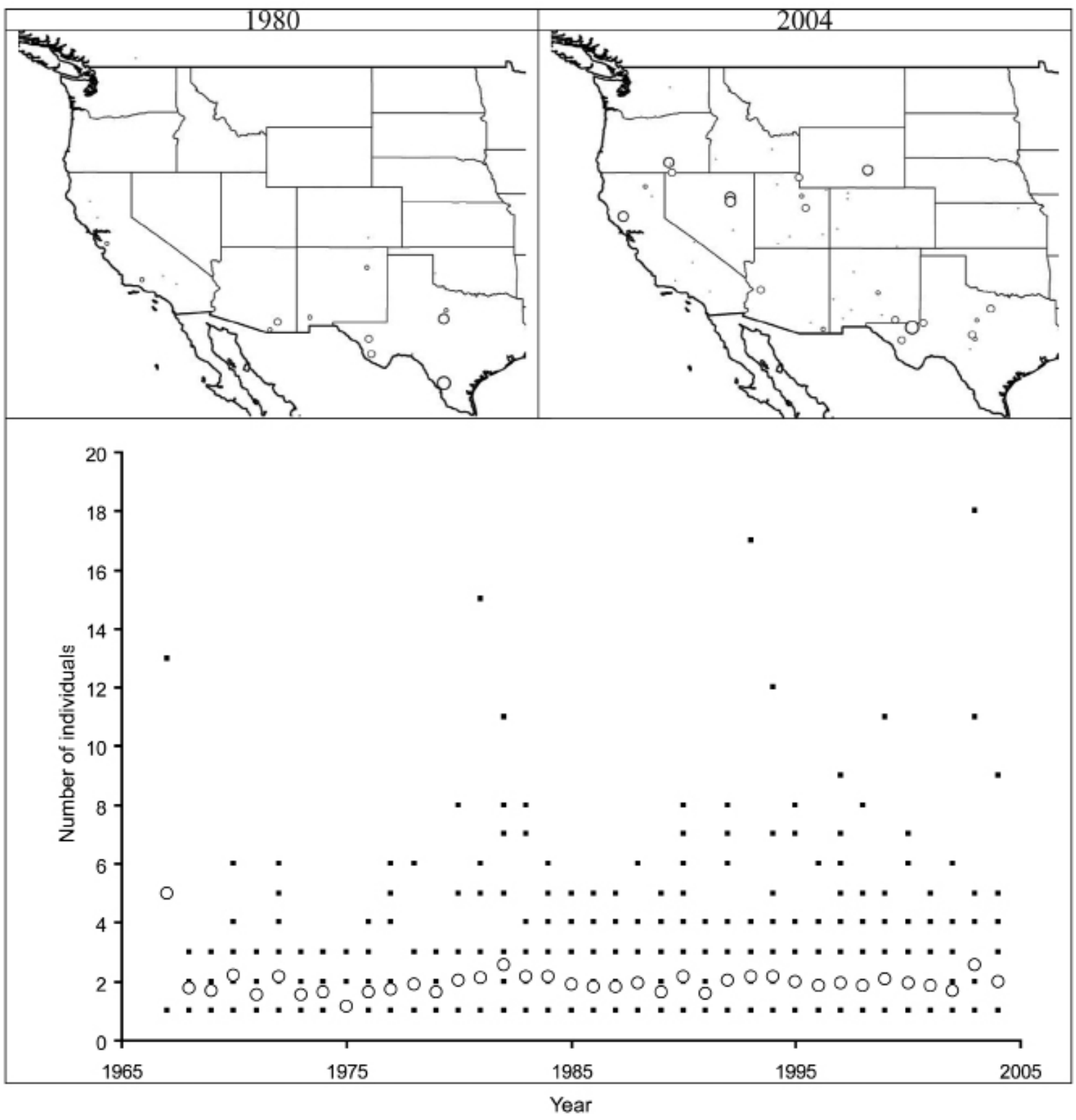

vve IIIEI ueveiupeu a sIIIpIe IIIIEal IEgIessivil IUI Eacil species, with $L_{\text {avg }}$ as the dependent variable, and year as the independent variable, taking probability values of $\leq 0.05$ as statistically significant. Finally, we were concerned that shifting patterns of coverage in the BBS effort could be producing the shifts in $L_{\text {avg }}$ that were observed in initial analyses. As a consequence, we restricted a second iteration of our analyses to only those survey routes for which $\geq 20 \mathrm{yr}$ of survey data were available, and repeated the analyses described above. Clearly, however, because numbers of routes are smaller in the 20-year data set, fewer species meet the sample size requirements.

\section{RESULTS}

Calculating the average latitude across all individuals tallied on 4726 U.S. Breeding Bird Survey (BBS 2006) routes in each year during 1960-2006, we regressed average yearly latitude on year to search for poleward population swells (Fig. 2; see methods below and summary table in Supplementary Information). Of 572 species tested, 261 showed significant northward population

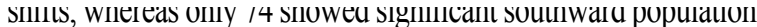
shifts and 237 showed no significant shifts. The imbalance between positive and negative shifts was statistically significantly different from expectations $\left(P<10^{-15}\right)$.

To guard against possible biases from historical shifts in distribution of survey routes, we repeated the analysis over 1829 survey routes for which time series of $\geq 20$ yr were available, and results were similar: 180 species increasing versus 33 species decreasing in average latitude, out of 378 species, with an associated probability of $P<10^{-14}$. Hence, even controlling for potential bias resulting from uneven spatial distribution of additions of routes to the BBS, the poleward population swell is clear across almost half of North American bird species. Results were similar when species were divided into terrestrial (193 increasing and 59 decreasing in latitude, out of 419 species) versus aquatic (34 increasing and 15 decreasing in latitude, out of 153 species), again indicating the widespread nature of the population shifts.
Figure 2.

Example map of a species (Common Poorwill, Phalaenoptilus nuttallii), showing strong northward shifts in distribution over the Breeding Bird Survey sampling period: (top left) distribution of individuals of the species in 1980; (top right) distribution of individuals of the species in 2004; (bottom) graph of numbers of individuals of the same species across all sampling transects in the BBS, showing individual transects (small black squares) and average latitude ( $L$; large white circles) through $1967-$ 2004. Circles on maps indicate numbers of individuals detected, with successive sizes (small to large) representing 1,2,3, 4-5, and 6-9 individuals detected. The high 1967 $L$ value is based on only 3 occurrences detected that year, as opposed to much larger sample sizes in succeeding years. 


\section{DISCUSSION}

The pervasive poleward population swells documented herein among North American bird species have several important implications for conservation. First, as can be appreciated in Fig. 1, population shifts will likely be followed by distributional shifts. This situation will have myriad implications for conservation efforts: presently well-situated reserves may no longer contain populations of the species that they were designed to protect, and discords among appropriate climate conditions and appropriate land cover types may arise (Peters and Darling 1985; Lovejoy and Hannah 2005). As such, we suggest serious reconsideration of the configuration of both current and planned protected natural areas to take into account ongoing climate change and the likely future configuration of distributional areas (Papeş 2006; Hannah et al. 2007) — clearly, this recommendation has serious implications, but the frequency with which we have observed species' numbers shifting northward strongly suggests dramatic range shifts in years to come.

More subtly, these results indicate the need for caution in interpreting estimates of overall trends in species' numbers, which has become a popular means of summarizing results of long-term monitoring data sets (Robbins et al. 1989; Butcher and Niven 2007; Butcher et al. 2007). Certainly, given our results, an overall 'species trend' would oversimplify the population processes that may differ in different sectors of species' distributions. Of particular note are species that are shifting in the northernmost tier of Breeding Bird Survey routes may appear to be in decline, when they are simply shifting out of the survey region populationwiserecent high-profile press releases and proposals for priority conservation status (Hamel 2000; Hunter et al. 2001) should be reconsidered in this light. In general, though, this study serves to indicate that the poleward, upward, and earlier shifts that have been documented in recent years (Parmesan 1996; Visser et al. 1998; Parmesan et al. 1999; Inouye et al. 2000; Crozier 2003; Parmesan and Yohe 2003; Nakazawa et al. 2007) are but the tip of the (melting?) iceberg. That is to say, we readily publish on the observed distributional or phenological shifts, and perhaps do not publish so readily on negative evidence (Peterson 2003; Archaux 2004). Nonetheless, among the large majority of species not as yet showing distributional responses to warming climates, based on the results of this study, many more are undergoing population shifts probably based on differential fitness across latitudinal gradients that will eventually manifest as real distributional shifts.

\section{ACKNOWLEDGMENTS}

We thank our colleagues at the University of Kansas and the Universidad Nacional Autónoma de México for ideas and discussion. This study was supported partially by the Instituto de Biología, Universidad Nacional Autónoma de México, and partially via a contract with Microsoft Research (to A. T. Peterson and colleagues).

\section{REFERENCES}

Archaux, F. 2004. Breeding upwards when climate is becoming warmer: no bird response in the French Alps. Ibis 146: 138-144.

BBS. 2006. North American Breeding Bird Survey (U.S. Geological Survey, http://www.mp2-pwrc.usgs.gov/bbs/, Washington, D.C.).
Brown, J. H., and M. V. Lomolino. 1998. Biogeography (Sinauer Associates, Massachusetts).

Butcher, G. S., and D. K. Niven. 2007. Combining data from the Christmas Bird Count and the Breeding Bird Survey to determine the continental status and trends of North American birds; http://stateofthebirds. audubon.org/cbid/content/Report.pdf (National Audubon Society, New York).

Butcher, G. S., D. K. Niven, A. O. Panjabi, D. N. Pashley, and K. V. Rosenberg. 2007. The 2007 WatchList for United States birds. American Birds 2007: 18-25.

Chapin, F. S. I., E. S. Zavaleta, V. T. Eviner, R. L. Naylor, P. M. Vitousek, H. L. Reynolds, D. U. Hooper, S. Lavorel, O. E. Sala, S. E. Hobbie, M. C. Mack, and S. Diaz. 2000. Consequences of changing biodiversity. Nature 405: 234-242.

Conti Nunes, M. F., M. Galetti, S. Marsden, R. S. Pereira, and A. T. Peterson. 2007. Are large-scale distributional shifts of the Blue-winged Macaw (Primolius maracana) related to climate change? Journal of Biogeography 34: 816-827.

Cresswell, W., and R. McCleery. 2003. How great tits maintain synchronization of their hatch date with food supply in response to longterm variability in temperature. Journal of Animal Ecology 72: 356-366.

Crozier, L. 2003. Winter warming facilitates range expansion: cold tolerance of the butterfly Atalopedes campestris. Oecologia 135: 648-656.

Dobson, A., A. Jolly, and D. Rubenstein. 1989. The Greenhouse Effect and biological diversity. Trends in Ecology and Evolution 4: 64-68.

Grinnell, J. 1917. Field tests of theories concerning distributional control. American Naturalist 51: 115-128.

Grinnell, J. 1924. Geography and evolution. Ecology 5: 225-229.

Hamel, P. B. 2000. Cerulean Warbler Status Assessment (U.S. Fish \& Wildlife Service, Washington, D.C.).

Hannah, L., G. Midgley, S. Andelman, M. Araújo, G. Hughes, E. MartinezMeyer, R. Pearson, and P. Williams. 2007. Protected area needs in a changing climate. Frontiers in Ecology and the Environment 5: 131-138.

Holt, R. D. 1990. The microevolutionary consequences of climate change. Trends in Ecology and Evolution 5: 311-315.

Hunter, W. C., D. A. Buehler, R. A. Canterbury, J. L. Confer, and P. B. Hamel. 2001. Conservation of disturbance-dependent birds in eastern North America. Wildlife Society Bulletin 29: 440-455.

Huntley, B., R. E. Green, Y. C. Collingham, and S. G. Willis. 2007. A Climatic Atlas of European Breeding Birds (Lynx Editions, Madrid).

Inouye, D. W., B. Barr, K. B. Armitage, and B. D. Inouye. 2000 Climate change is affecting altitudinal migrants and hibernating species. Proceedings of the National Academy of Sciences USA 97: 1630-1633.

IPCC. 2007. Climate Change 2007: The Physical Science Basis (Cambridge University Press, Cambridge).

Lovejoy, T. E., and L. Hannah (Eds). 2005. Climate Change and Biodiversity (Yale University Press, New Haven, Conn.).

Nakazawa, Y., R. Williams, A. T. Peterson, P. Mead, E. Staples, and K. L. Gage. 2007. Climate change effects on plague and tularemia in the United States. Vector Borne and Zoonotic Diseases 7: 529-540.

Papes, M. 2006. Ecological niche modeling approaches to conservation of endangered and threatened birds of Central and Eastern Europe. Biodiversity Informatics 4: 14-26.

Parmesan, C. 1996. Climate and species' range. Nature 382: 765-766.

Parmesan, C., N. Ryrholm, C. Stefanescu, J. K. Hill, C. D. Thomas, H. Descimon, B. Huntley, L. Kaila, J. Kullberg, T. Tammaru, J. Tennent, J. A. Thomas, and M. Warren. 1999. Poleward shift of butterfly species ranges associated with regional warming. Nature 399: 579-583.

Parmesan, C., and G. Yohe. 2003. A globally coherent fingerprint of climate change impacts across natural systems. Nature 421: 37-42.

Perfors, T., J. Harte, and S. E. Alter. 2003. Enhanced growth of sagebrush (Artemisia tridentata) in response to manipulated ecosystem warming. Global Change Biology 9: 736-742.

Peters, R. L., and J. D. S. Darling. 1985. The Greenhouse Effect and nature reserves. BioScience 35: 707-717.

Peterson, A. T. 2003. Subtle recent distributional shifts in Great Plains endemic bird species. Southwestern Naturalist 48: 289-292.

Robbins, C. S., J. R. Sauer, R. S. Greenberg, and S. Droege. 1989. Population declines in North American birds that migrate to the Neotropics. Proceedings of the National Academy of Sciences USA 86: 7658-7662.

Root, T. L., J. T. Price, K. R. Hall, S. H. Schneider, C. Rosenzweig, and J. A. Pounds. 2003. Fingerprints of global warming on wild animals and plants. Nature 421: $57-60$

Visser, M. E., A. J. van Noordwijk, J. M. Tinbergen, and C. M. Lessells 1998. Warmer springs lead to mistimed reproduction in great tits (Parus major). Proceedings of the Royal Society B 265: 1867-1870.

Walther, G.-R., E. Post, P. Convey, A. Menzel, C. Parmesan, T. J. C. Beebee, J.-M. Fromentin, Hoegh-Guldberg, and F. Bairlein. 2002. Ecological responses to recent climate change. Nature 416: 389-395. 